\title{
CORRECTION
}

\section{Correction to: Evaluation of Volumetric Change of Intracerebral Hemorrhage in Patients Treated with Thrombolysis for Intraventricular Hemorrhage}

Franziska Staub-Bartelt ${ }^{1 *}$, Jasper Hans van Lieshout ${ }^{1}$, Thomas Beez ${ }^{1}$, Rainer Kram² ${ }^{2}$ Daniel Hänggi ${ }^{1}$ and Kerim Beseoglu

C 2020 Springer Science+Business Media, LLC, part of Springer Nature and Neurocritical Care Society

\section{Correction to: Neurocrit Care}

https://doi.org/10.1007/s12028-020-01054-7

The original article has been updated:

The author name Kerim Beseoglu has been corrected and the details given in this correction are correct.

\section{Author details}

${ }^{1}$ Department of Neurosurgery, Medical Faculty, Heinrich-Heine University Düsseldorf, Moorenstraße 5, 40225 Düsseldorf, Germany. ${ }^{2}$ Department of Anesthesiology, Medical Faculty, Heinrich-Heine University Düsseldorf, Düsseldorf, Germany.

\section{Publisher's Note}

Springer Nature remains neutral with regard to jurisdictional claims in published maps and institutional affiliations.

Published online: 26 August 2020

*Correspondence: Franziska.staub-bartelt@med.uni-duesseldorf.de

${ }^{1}$ Department of Neurosurgery, Medical Faculty, Heinrich-Heine University Düsseldorf, Moorenstraße 5, 40225 Düsseldorf, Germany

Full list of author information is available at the end of the article

The original article can be found online at https://doi.org/10.1007/s1202 8-020-01054-7.

\section{实 Springer}

